August - 2004

\title{
Faculty Opinions towards Introducing e-Learning at the University of Bahrain
}

\author{
Muain Jamlan \\ University of Bahrain
}

\begin{abstract}
E-Learning is an important tool for delivery, interaction, and facilitation of both teaching and learning processes. Faculty members at the University of Bahrain's College of Education are being encouraged to become involved in e-learning activities. To assess faculty opinions on elearning, a questionnaire was sent to 30 faculty members of the University's College of Education to determine how they perceive e-learning, and how they might choose to integrate it into their everyday teaching activities. Data was collected and analyzed by using descriptive statistics. Results indicate that faculty generally perceive e-learning as a positive force in helping students' achieve their learning objectives. Answers to this questionnaire, however, also indicated areas of weakness: specifically that baseline technological and human resource prerequisites are necessary to support e-learning, and that these baseline prerequisites are not yet available at the University of Bahrain. Other baseline prerequisites are: staff training, well prepared online courses and learning materials, sufficient groundwork for the smooth transition from traditional modes of learning towards e-learning delivery, and the implementation of a more robust technological infrastructure to support all the technical aspects necessary to launch and sustain e-learning.
\end{abstract}

\section{Introduction and Literature Review}

Educational processes have undergone many of changes during the last century. From print learning materials mailed to students' homes, to educational radio broadcasts, to educational television programming, to recent forays in interactive Web-based e-learning, ongoing technological changes have been reflected in the evolving role of teachers and students in the learning equation. Technological changes - particularly Web-based e-learning technologies have resulted in new curriculum design and teaching strategies, new and emerging organizational structures, and it has even transformed learning itself. McKenzie (1998) said that technology would transform the act of teaching, whether or not teachers or students are ready for this inevitable change. According to McKenzie, when faced with new technology, students and/ or teachers would likely adopt one of two approaches: they would either embrace it or they would dismiss it. In other words, teachers and students will either learn how to use new technology, or they would ignore it - the later of which would put them at disadvantage compared to their more technologically literate peers. Ballard opined that technology is reshaping today's school systems and educational institutions by offering students new ways of seeing and learning; giving teachers new ways of teaching and imparting knowledge; and administrators new ways of organizing our educational system (Ballard, 2000). 
Innovations in teaching and learning have emerged, and educators are in the midst of becoming more adept at using new educational technologies. This fact is reflected in our changing language. Terms such as "open education," "distance education," "distance learning," "virtual learning," "remote learning," "online learning," and "e-learning” are now part of educators' everyday lexicon. Use of such terminology helps to define and shape the creative innovations taking place. However, many overlaps can be seen within these terms. Urdan and Weggen (2000), for instance, found that that online learning constitutes just one part of e-learning; and further define it as learning processes that take place via the Internet and in blended classroom contexts. They specified that e-learning covers a wide spectrum of applications and processes, including virtual classrooms and digital collaboration.

With the introduction of the Internet, an invention of the US Military designed for robust communication and sharing of scarce resources, and CERN (http://public.web.cern.ch/public/ ) the world's largest particle physics laboratory and the birthplace of the Web (Hauben, 2002), there has been a boom in applications commonly known as e-business, e-commerce, egovernment, and e-learning. However, as these technologies are applied in different geographic and cultural contexts (such as Bahrain), their application is often not so clear cut. How is Webbased technology used in a given cultural/ educational context? How effectively will it work? How will people deal with it? Educators the world round are seeking to come to grips with the human complexities of Web-based learning technologies.

To explain what "exactly" is taking place, terms are helpful. However, terms are still being defined. The term "e-learning," for example, has generated many different definitions according to Carry and Willis (2001), who broadly define e-learning as any form of learning that utilizes a computer or technological network for delivery, interaction, or facilitation. Becker (1991) opines that e-learning covers a wider set of applications and processes, which include Web-based learning and virtual classrooms. Hall and Snider (2000) define e-learning as the process of learning via computers over the Internet and Intranets. For the purposes of this article, the author will say that e-learning can be defined as "acquisition and use of information distributed and perceived by technological means.”

Definitions are important, and when one adds the ability of the Internet to bridge time and space, e-learning truly has the ability to re-invent itself again and again, particularly when it is applied in different cultural contexts. Digital educational delivery knows few, if any, boundaries. e-Learning has the ability to bridge cultures and open doors to new ways of thinking. Clearly such implications are beyond the scope of this article, but are important to consider when introducing a new learning technology into any cultural context.

Cultural implications aside, there are several cogent reasons for adopting and implementing elearning into an educational system:

1. The growth of information technology: e-Learning has become an ideal delivery vehicle for education and learning

2. It is information rich: e-Learning offers both teachers and learners access to any where, any time "information rich" resources

3. Alternative learning strategy: e-Learning can reach those previously denied access (e.g., students with physical disabilities) 
4. Blended learning: e-Learning can augment traditional classroom offerings, thereby freeing up valuable resources and expanding the offering to greater numbers of campusbased students (Spender, 2001).

In light of e-learning's flexibility, Spender (2001) asserts that e-learning is the next generation of learning. However, Spender also cautions that the shelf-life of knowledge is usually very short in today's globalizing economy; therefore, one way students can meet the demands of their continuous learning curve, is to engage in e-learning a time and place convenient to them. eLearning thus derives numerous benefits to meet the objectives of continuous learning. It:

- Offers links to useful learning materials

- Provides online materials and self-assessments to guide students' learning processes

- Increases access to content-rich learning materials

- Facilitates interest via increased interaction

- Provides immediate feedback and positive reinforcement

- Creates a flexible learning environment conducive to students' busy lifestyles and employment schedules

- Provides ongoing support for teachers

- Creates balance between different sources of information

- Facilitates dialog between and among teachers and students (Haugland and Wright, 1997)

The literature examines the importance and benefits of e-learning as an educational tool. The literature also shows that educators are concerned with increasing student access to educational resources and communication processes (Hartly and Robertson, 2001). Nonetheless, when introducing e-learning into a new context, "buy-in” from teachers is essential. Put simply, even though there is a recognized need for increased access, e-learning technologies cannot be used effectively without the full support of those who will use them (e.g., faculty and staff). For example, teachers must transition away from traditional methods of teaching, towards a more constructivist pedagogy that will enable students to derive full benefit from e-learning (O’Donnell, 1991). The literature also shows that teachers who hold "less traditional" views on education, are more likely to perceive e-learning a viable approach in their everyday teaching activities (Becker, 1991; Hannafin and Savenye, 1993; Kook, 1997; O’Donnell, 1991; Salmon, 2000) and that in general, teachers tend to hold positive attitudes towards e-learning (Kleiman, 2000; Minton, 2000; Teather, 2000).

But the process is more complicated that simply saying teachers are "open to e-learning." According to Mason (2001), comprehensive staff training initiatives are necessary to allow those involved to become proficient in the technical and educational aspects of e-learning. Training initiatives must integrate "learning about educational design" with hands-on "learning how to use the technological devices and tools" to teach. Teachers therefore must be encouraged to become active participants in the design and implementation of e-learning processes, instead of having it imposed upon them. Involving teachers in the design and implementation phases compels them to 
become proactively involved, and more importantly, supportive of e-learning initiatives at the institutional level (Mason, 2001).

For e-learning to take root and grow, a robust technical infrastructure must also be in place to support all the technical aspects necessary for the production of course materials, delivery of elearning courses, and teacher and student support (Mason, 2001).

Implementing e-learning in an institutional setting therefore requires comprehensive strategic planning. Davidson and Schofield (1997) stated that changing the educational offering through technology requires employing effective implementation plans and strategies. For example, sound e-learning course planning requires attention to developing course contents that include sound pedagogical underpinnings, and are suited for e-learning delivery (Biddara and Dias, 2003). Attention to various sub-strategies to facilitate the adoption e-learning is also required to ensure seamless integration of e-learning across an organization. Planning is clearly a complex process, one which should ideally be institution-specific (Davidson and Schofield, 1997).

At the University of Bahrain, Jamlan (2002) asserts that adoption of an e-learning model should not happen quickly, nor should it be based on an inflexible transition process. Instead, the transition to e-learning at the University of Bahrain should be flexible, gradual, and integrate with existing structures, processes and organizational cultures. According to Jamlan, "buy-in" among those individuals needed to bring about such transition at the University of Bahrain is essential. It therefore is best to combine old processes with new (e.g., educational strategies, etc.), and by substituting the old with the new, until a final "desired" model of e-learning emerges that "fits" the educational and cultural contexts unique to the University of Bahrain. Jamlan also asserts that to successfully implement e-learning, a supportive technological infrastructure must be in place, and it must be resourced with the human expertise necessary to design curriculum, offer student support, teach effectively, etc (Jamlan, 2000).

Collaboration with other institutions engaged in similar e-learning initiatives is also desirable to lower costs of introducing such a system. Laurillard (2002) concluded that collaboration with external organizations is a "must" for educational institutions contemplating introducing elearning into its educational offerings. McKenzie (1998) furthers Laurillard's work, contending that the implementation of e-learning educational offerings and supportive infrastructure must not be rolled out piecemeal, but instead be an entrenched element of an overall educational budget in order realize economies of scale (i.e., leveraging work and resources to lower human resource costs and expenditures on space, resources, and equipment).

Implementation of e-learning also requires that quality assurance procedures be put in place, including regular measurements such as surveys to determine if students do, in fact, receive adequate access to technology and are recipients of effective e-learning (Magnusson and Svensson, 2000).

\section{The Case for the University of Bahrain}

It is clear from the brief literature review above, that "buy-in" from faculty, support staff, and students - those who will be using the system - is central to its long-term success. This paper presents the results of a survey undertaken to gauge how the University of Bahrain's faculty members perceive e-learning. Results of this investigation are anticipated to add a Bahrain perspective to current literature on this subject. It is suggested that other educational institutions in the region, and throughout the world, might also benefit from the findings of this survey. 


\section{Background}

Bahrain, like other countries around the world, is exposed to the Internet and its various technical applications. As such, Bahrain is seeking to maximize its potential in all sectors of its economy, from government to the private sector. The Internet has application in many aspects Bahrain life, from commerce and banking to education and entertainment - e-government, e-commerce, elearning, being some of the more popular applications. It is easy to access the Internet in Bahrain, and its popularity has now grown beyond that of a plaything or luxury, to that of necessity.

There have been several attempts over the past decade to utilize and integrate the Internet into Bahrain educational system, beginning with the introduction of computer literacy courses in the nation's high school classrooms in the early 1990s. First emphasis was placed on courses examining the history of computers, its components, and keyboarding skills. Over the last decade, however, Bahrain's computer education curricula have evolved to include: computer operations, applications, and technology. During this decade, a dedicated network was also established to connect all the computer laboratories in all the nation's schools. To stay abreast of these changes, teachers attended in-service workshops to learn how to use computers on a personal level and in their teaching activities.

Currently, attempts are being made by the Directorate of Curricula at the Ministry of Education to teach some aspects of the schools' curriculum online, delivered via this network. To date, however, there has been no integrated attempt to convert courses for online delivery in a coherent manner. Nonetheless, efforts are being made by Bahrain's Directorate of Curricula to deploy an integrated infrastructure and processes dedicated to e-learning. In the meantime, ad hoc attempts are underway in some schools to deliver some didactic materials online to targeted groups of students. But these ad hoc attempts are piecemeal and exploratory, and will eventually be superceded by a more comprehensive system. However, certain technological - and more importantly cultural conditions - must be accessed and addressed before a coherent e-learning strategy in Bahrain's school system can be successfully introduced.

\section{The University of Bahrain's Experience}

The University of Bahrain has enjoyed a head start over that of the nation's lower schools (primary, intermediate and secondary), which are under the control of Bahrain's Ministry of Education. It is only logical, therefore, that the University of Bahrain share its knowledge and leverage its expertise, possibly by providing the foundation for the inevitable deployment of elearning across the country.

The University or Bahrain has a long history in computing sciences. In early 1980s, the University's department of computer sciences was established to offer a BSc degree in computing sciences, followed shortly thereafter by a department of computer engineering established under the umbrella of the College of Engineering. These two departments, along with the department of business information systems, were merged in 2000 to create the current College of Information Technology, responsible for teaching computer and information technology at the University. Nonetheless, other colleges are also seeking to integrate computer and information technology into their educational offerings. The department of educational technology at the College of Education for example, offers a BSc degree in Educational and Information Technology - a trend that is being repeated in all the University's colleges. To ensure that work is not duplicated, and to coordinate the various activities underway across all the colleges, the University of Bahrain's 
Information Technology Center offers technical services to all departments at the university and is responsible for information technology access campus wide.

e-Learning at the University of Bahrain originally emerged in response to the introduction of the Internet and related computer applications. Like other universities around the world, especially those in Europe and North America, the Internet was first introduced at the University of Bahrain in early 1990s. Email was the most widely used Internet application at that time, but its use was restricted (only faculty and certain administrators specializing in computer and information technologies initially had access to the Internet). At that time, virtually no thought was paid to the didactic potential of the Internet or e-learning. With ever increasing availability of Internet access across the campus, coupled with exponential growth of computing capacity, by the mid to late 1990s e-learning emerged to become a realistic alternative for those faculty interested in teaching online. A decade later, however, e-learning still remains a mere option at the University, and efforts to deploy e-learning currently remain purely ad hoc. There is no systematic use of elearning across the University to lead students to a certificate or degree. And while it is true that some departments use e-learning in selected course offerings, the fact is that no comprehensive elearning system is in place to guide the future expansion of e-learning activities in a holistic, comprehensive manner. And while training workshops on how to use e-learning and develop elearning materials have been offered, and software packages are made available to those wishing to engage in e-learning, no comprehensive or compelling strategy to guide universal e-learning deployment at the University is in place either. Nonetheless, several viability studies have been carried out, all of which cite the applicability of e-learning at the University. Similarly, several proposals to make e-learning available have been tabled. These activities reveal the University's clear and present interest in e-learning. In short, the University's administration is fully aware of the impact e-learning is having in terms of both need and potential, and are they are responding by seriously examining the implementation of a comprehensive e-learning strategy to coordinate and leverage its multiple efforts underway in all its departments and colleges. Clearly, such an effort to coordinate and harness these activities is a huge undertaking, and it will take a tremendous amount of strategic planning and effective leadership to make it happen.

To achieve this end, an e-learning center has been proposed to take responsibility for the comprehensive implementation of all e-learning activities across the University. Entire programs based on e-learning study are being planned. Similarly, other e-learning related activities and initiatives, such as live teleconferencing (which is currently hardly used at the University), will be taken into account in planning the scope of the larger implementation plan. Much good work has taken place at the University of Bahrain, albeit in a scattered, ad hoc manner. The objective here, therefore, is to examine what the University has accomplished to date, and to take the "parts that work well” and incorporate them into the larger plan.

Despite the ad hoc forays into e-learning at the University of Bahrain, it remains important to discuss all the issues and ramifications of implementing e-learning. Those charged with designing this strategic framework must take stock of what has happened, and determine how to use this technology to the University's (and Bahrain's) overall competitive advantage. Those charged with this project must explore and find answers to such questions as: Why this the University seeking to integrate e-learning? What kind of e-learning must be adopted and in what context? How is it going to be implemented? How do we measure student success in e-learning? How do we measure the impact e-learning will have on society? Clearly, the University of Bahrain, like other educational institutions throughout the world, is being forced to critically examine how they want to derive benefit from the Internet and e-learning. 
Knowing exactly how staff, faculty, and students perceive e-learning and Web-based technologies, is an important first step. While technology itself is inhuman, how people use technology remains very human. The way in which education is offered via the Web clearly influences students' comprehension of study materials, as well as faculty members' use of electronic teaching materials. Faculty members, by benefit of experience and training, know that learning via the Web can take place, but that it will require different or modified pedagogical methods and strategies to make it happen effectively. Some e-learning applications can enhance student learning, whereas in other instances it might not yield such impressive results. And while faculty members may feel that e-learning will better meet students' needs and desires in terms of offering flexible educational opportunities anytime and anyplace, the fact remains that little is known about how students learn online. Simply put, using e-learning in some contexts might not be such a wise investment, as compared to similar courses offered in traditional face-to-face classroom settings.

Bahrain is a young country. Those under age 14 comprise nearly 30 percent of the nation's population (GE Source, World Guide, 2004). Faced with a large population of young people that need to be integrated into Bahrain's higher educational system over the coming years, the University of Bahrain must seriously examine e-learning as a solution to classroom overcrowding (for both blended learning situations or entire programs of study). Our ad hoc experiences tell us that certain courses can be taught successfully at a distance via e-learning modalities, and it is this "ad hoc experience" that we are seeking to measure and evaluate, to see what works and what does not.

Another question that needs to be answered is: What kind of e-learning should be developed inhouse, outsourced, or purchased in a box? Answers to this question rely upon numerous factors, such as what kinds of technologies are currently available, faculty's familiarity with technology, physical access to the Internet, students' perceived and real needs, and the types, quality, and quantity of e-learning courses on offer. Once answers to these and other questions are found, it is anticipated that the University will likely adopt a hybrid approach to e-learning, one which includes developing individual courses used in blended learning situations, and/or entire programs of study offered solely online.

How should the University of Bahrain implement e-learning? Research shows that is it not prudent to adopt new e-learning strategies without first fully understanding the human/ cultural underpinnings (Hara and Kling, 2000) and physical/ technological infrastructure needed to support it (Fahy, 1999). Without first defining and answering such questions, roadblocks could arise, and e-learning could become a costly "bauble" that is nice to show off, but not worth much in terms of the value it adds to those working towards completing a course or degree. What sort for technological infrastructure is necessary? Is the technology scalable as demand increases? Are staff and faculty adequately prepared to support students learning online? Do they know how to use the technology themselves, as well as understand how students should ideally interact with it? Do students know how to interact with teachers, tutors, and fellow students online? Clearly, elearning entails much more effort than simply putting textbooks online.

While it is important to impress upon University's of Bahrain's decision makers the importance to act upon e-learning, it is equally important to ensure that any efforts undertaken are made in such as manner that all contingencies are planned for in advance. It is not a case of hurry up, implement e-learning fast, and see what happens. It is ensuring we have the right framework in place, and ensuring all work is done right the first place. 
When viewed from this perspective, Jamlan (2000) asserts that the University of Bahrain is not yet ready to adopt e-learning. Vital steps must first be taken to ensure that e-learning does not become costly "bauble.” According to Jamlan, the University's technological infrastructure is currently not robust enough to support a comprehensive e-learning initiative. Similarly, faculty and support staff are not yet prepared for what many perceive as a radical change to their teaching methods and everyday work - they may either fear or simply lack the expertise to use such technology effectively. Without the necessary level of technological and human resources available, it will be difficult to sustain the collective teamwork necessary to overcome the obstacles typical to implementing a large-scale e-learning project. Once these underlying technological and human issues and concerns are addressed, however, the roll out of comprehensive e-learning initiative across all the colleges and departments of the University of Bahrain should go more smoothly.

Students are likewise an important factor in the mix of potential problems may arise. Close attention must be paid to students' perceived expectations versus their actual learning needs. Like teachers, students tend to be creatures of habit and used to status quo teaching methods. While it is clear that changes must take place within Bahrain's learning system, it must be at a pace that students are comfortable with. Students must therefore be strategically transitioned to e-learning and not simply dumped into the deep-end of the ocean and told to sink or swim. Students must be transitioned from the teacher-centric environment found in traditional classroom settings, to a student-centric model of e-learning where students are in charge of their own learning outcomes, and where teachers' roles move from the "sage on the stage" to "proactive facilitators of learning." Students must first be taught "how to learn." They must be given access to the new tools (e-learning) and taught how to self-direct their learning - necessary elements in a studentcentric environment, which is a typical outcome e-learning. This will require that students transform how they perceive their teachers' role, and as such, plans must be in place to transition them towards a fundamentally different view of how they perceive their teachers' work. But before we examine students' perceptions at the University of Bahrain, we must first examine how teachers perceive their role. And this leads us to the core of this paper.

Gauging faculty members' opinions towards e-learning is a crucial first step towards the successful adoption of e-learning. It is important to determine the level of faculty members' interest in e-learning, and how they perceive e-learning as either a similar - or different teaching strategy from what they are currently using. Teachers tend to have a certain comfort level and familiarity teaching with established facilities such as classrooms, blackboards, video and audio cassettes, printed materials, and basic computer applications (i.e., Microsoft Office). However, to move faculty and staff forward into e-learning, we must first determine how faculty members feel about and perceive e-learning. Such perceptions are typically either based on hands-on experience or second-hand knowledge. A clear understanding of teachers' perceptions, therefore, will help construct a strategy to smoothly implement e-learning at the University. Determining perceptions will also help determine whether to continue using existing e-learning elements based on personal understanding and ad hoc use, or if a more generalized approach for e-learning deployment should occur. In sum, the results of this survey will help the University to develop a "how to deploy" policy. It is anticipated the findings of the survey (outlined below) will help guide decision makers at the University, and perhaps guide other educational institutions develop appropriate e-learning solutions for their particular goals and unique cultural contexts.

As mentioned, some faculty members are already using some kind of e-learning and this fact may, in itself, be a problem - or it might not be. The data gathered from this questionnaire will therefore help make sense of current levels of e-learning usage at the University, and give 
administrators the basic data they need to define and develop future, comprehensive e-learning initiatives. To date, however, there have been no studies undertaken to determine the exact opinions held by the College of Education faculty members on e-learning.

\section{Purpose}

It was felt that by undertaking a detailed study, hidden issues could be brought to light and addressed to ensure these issues do not impede the adoption of e-learning at the University of Bahrain's College of Education. By identifying both the obstacles and the positive attitudes held by faculty members, the results of this study could form the basis for a College-wide e-learning implementation plan. The results could also be used to build future efforts aimed at implementing e-learning not only in the College of Education, but in other Colleges throughout the University of Bahrain. It is anticipated that with the implementation of e-learning at the College of Education, the role of faculty members will be transformed from that of traditional dispensers of knowledge (sage on the stage), to learning facilitators (student-centric model). It is also anticipated that by involving staff in building a e-learning modality unique to University of Bahrain, this "collaborative approach" would greatly improve faculty opinion towards e-learning, and give rise to grassroots level confidence building as faculty work hands-on to integrate elearning into their current course mix and teaching strategies.

\section{The Question}

"What are the opinions of the faculty members at the college of education at the University of Bahrain towards introducing e-learning in their teaching strategy?”

\section{Sample}

Using the stratified random sampling technique to include both male and female staff, 30 participants (61.2 percent) selected for this study were drawn from a total pool of 49 faculty members of the College of Education, University of Bahrain.

\section{Method}

One instrument (a questionnaire) was used to determine faculty opinions towards introducing elearning in their teaching strategies at the College of Education. The questionnaire consisted of 20 positively and negatively phrased statements to preclude any response set. Several items, used in other questionnaires from other studies (Fournier, 2002), were re-phrased for this study. The questionnaire was designed to be applicable to the study's population in terms of actual and perceived working conditions. A five point Likert scale was used consisting of: 1) strongly agree; 2) agree; 3) not sure; 4) disagree; and 5) strongly disagree.

The first draft of the questionnaire was sent to a panel of referees to determine its relevancy and validity. Minor changes were suggested by the referees. Upon re-examination of a second draft, consensus among the referees on the questionnaire's design and validity reached 88.3 percent, indicating a strong validation of the questions used in the questionnaire (Nitko, 1996). A correlation coefficient, calculated 0.90 on Alfa-Cronbach value, was used to test the internal reliability of the questionnaire, indicating strong reliability ( Nitko,1996, p. 69). The final questionnaire (see appendix) was delivered to the sample of the study via regular mail. 


\section{Data Analysis}

Descriptive statistics were calculated by using the Statistical Package for the Social Sciences (SPSS) software. Statistical findings for the opinion measures found in the questionnaire are reported in Table 1.

Table 1. Mean and Standard Deviation

\begin{tabular}{|c|c|c|c|}
\hline Question & Stateruent & lilear & $\begin{array}{l}\text { Stardard } \\
\text { Deviatior }\end{array}$ \\
\hline 3 & $\begin{array}{l}\text { Saves tirue ard efforts of both teachers ard } \\
\text { studerts }\end{array}$ & 4.57 & .50 \\
\hline 15. & Techuological infrastructure is crucial & 4.43 & .50 \\
\hline 1. & Provides rich resources & 4.40 & .97 \\
\hline 6. & Provides rassive education for learuers & 4.37 & .81 \\
\hline 13. & Veeds well prepared orline ruaterials & 4.33 & .48 \\
\hline 12. & $\begin{array}{l}\text { Weeds sufficient training courses for } \\
\text { implernentation }\end{array}$ & 4.30 & .84 \\
\hline 17. & Irstitutional recogrition of e-learring & 4.10 & 80 \\
\hline 19. & Establishirg Evaluation mecharism & 4.10 & .88 \\
\hline 14. & Suffic ient ground work is required & 4.07 & 83 \\
\hline 2. & Provides efficiency in teaching & 4.03 & 1.38 \\
\hline 18. & Establishirg support services such as multiruedia & 4.03 & .93 \\
\hline 16. & Variant teaching strategies are required & 397 & .96 \\
\hline 11. & Stardardias the content of course raterials & 393 & 1.11 \\
\hline 10. & Miririzes costs of teaching arid learrirg & 3.83 & 95 \\
\hline 20. & Irrplementation should be gradual & 3.73 & 1.11 \\
\hline 8. & Diffienlty in rovritoring evaluation process & 3.67 & 1.09 \\
\hline 7. & Easy to rnoritor teaching and learrirg processes & 3.43 & 1.17 \\
\hline 9. & Fesults ir decline ir le arrers" achieve ruent & 2.73 & 1.17 \\
\hline 5. & $\begin{array}{l}\text { Causes fragmentation of work and loss of } \\
\text { consistency in learning }\end{array}$ & 2.53 & 1.25 \\
\hline 4. & $\begin{array}{l}\text { Feduces tearmork ard collaboration betwern } \\
\text { students }\end{array}$ & 2.50 & 1.25 \\
\hline
\end{tabular}

The mean data shown in Table 1 indicates there were no negative opinions towards using elearning held by College of Education faculty members. Only a small portion ( 2.5 percent) of those surveyed tended to hold negative opinions toward the introduction of e-learning. The standard deviation also reveals the spread of the score distribution to be small for most of the items, indicated that faculty members tend to hold similar opinions towards the statements about e-leaning. The data collected also indicated the extent to which survey respondents provided similar responses or ratings in answering the questions. When respondents provided the same or highly similar responses, the standard deviation of their responses was small, as is shown in the survey response in Table 1. In sum, the data collected revealed that the University's College of Education faculty generally held positive opinions towards introducing e-learning.

The statistical findings for the opinion measures used in the questionnaire are reported as "frequency" and "percentages." This analysis uses the frequency procedure to tabulate the counts and calculate the percentages. The total for the percentages derived were congregated into five groups: 1) strongly agree; 2) agree; 3) not sure; 4) disagree; and 5) strongly disagree. This analysis presents the statistical findings for measure of faculty opinions towards introducing elearning in their teaching strategies. 


\section{Discussion}

Results of this investigation revealed "commonly held opinions" among faculty members on the introduction of e-learning at the College of Education. These results indicate that faculty members tend to view e-learning positively. They were of the opinion that e-learning will benefit teachers, students, and learning in general. Results of this study echo earlier studies by Kleiman (2000), Minton (2000), and Teather (2000). In spite of these positive findings, some reservations toward e-learning were nonetheless revealed in the data. Most faculty surveyed expressed concern that the introduction of e-learning would require increases in staff and student numbers to make e-learning economically viable.

Results of this study also revealed other widespread opinions on the introduction of e-learning:

- e-Learning provides rich resources to students and teachers

- e-Learning can make teaching more efficient

- $\quad$ e-Learning can save teachers and students time and effort

- $\quad$ e-Learning provides students greater access to educational opportunities

In summary, the results of this survey reinforce outcomes of similar studies conducted by Haugland and Wright (1997) and Hartly and Robertson (2001). While it remains to be seen if elearning can live-up to faculty's current expectations and perceptions, it does indicate they are open to the possibilities offered by e-learning.

Whether based on reality or wishful thinking, other commonly held perceptions/ opinions among College of Education faculty members are:

- It is easy to monitor teaching and learning processes via e-learning

- $\quad$ e-Learning can minimize costs

- $\quad$ e-Learning can help to standardized course contents and learning materials

Survey results also indicated that faculty members do not perceive that e-learning reduces teamwork and collaboration between students, or causes fragmentation of work and loss of consistency in learning, or results in a decline in learner achievement.

These finding are encouraging and support the University of Bahrain's College of Education adoption of e-learning. It is anticipated that e-learning will be met with minimal resistance internally. Nonetheless, this survey also revealed key weaknesses. Faculty members are of the opinion that the monitoring and evaluation processes via e-learning might be difficult. Results also indicate that many requirements must be fulfilled before implementing e-learning at the University's College of Education: teachers and students must have sufficient training; they must have access to well-prepared online course and teaching materials; sufficient groundwork must be laid to ensure that the adoption of e-learning is embraced by all involved. More importantly, the survey also reveals that the transition towards e-learning must be done gradually. In sum, results of this study reinforce the earlier findings of Davidson and Schofield (1997), McKenzie (1998), Mason (2001), Jamlan (2002), and Laurillard (2002). 


\section{Conclusion}

It is hoped that this study will contribute to a better understanding of faculty opinions towards introducing e-learning at the University of Bahrain's College of Education. Overall, the results indicate that faculty members tend to view e-learning positively. These findings are consistent with those found in the current literature. Current literature indicates that training is necessary before students and teachers are exposed to e-learning. A clear strategy is therefore required prior to implementing e-learning. The survey also reveals that gradual implementation is desirable, until faculty are comfortable using e-learning technology and convinced of its application as a viable teaching/ learning delivery strategy. Results of this study are anticipated to strengthen the status of e-learning at the University and other distance learning institutions in the region, and other areas of world. Some important outcomes of this study point to the need for further investigation. Many questions have yet to be answered. Does e-learning increase or decrease teamwork and collaboration among students? What is the best method to monitor student progress in specific learning contexts? Is standardized content better than customized content? And if so, in which contexts is standardized content better? What are students' opinions towards e-learning? Clearly, research on e-learning is as broad and potentially complex as the technology itself. Future research may take on a collaborative form, with the University of Bahrain working in partnership with other universities throughout the world. Similar cases examining whether to, and how to, implement e-learning are in the process of evaluation. Ad hoc experiences are still happening in e-learning, and their outcomes need to be fully analyzed and assessed for their effectiveness.

\section{References}

Ballard, R. (2000). Networking K-12 Education. Retrieved April 25, 2004 from: http://www.abegs.org/fntok/htm

Becker, H. (1991). When Powerful Tools Meet Conventional Beliefs and Institutional Constraints. Computing Teacher, 18(8), 6 - 9.

Biddara, J., and Dias, A. International Review of Research in Open and Distance Learning, 4(2). Retrieved April 22, 2004 from: http://www.irrodl.org/content/v4.2/bidarra-dias.html

Carry, D., and Willis, J. (2001). Technology and Teacher Education. Association of Advancement of Computing in Education. Charlottesville, VA.

Fahy, P. J. (1999). Reflections on the Productivity Paradox and Distance Education Technology. Journal of Distance Education 13(2). Retrieved July 14, 2004 from: http://cade.icaap.org/vol13.2/fahy.html

Fournier, B. (2002) e-learning in Europe. Noir Sur Blanc, 3(1), 1 - 24.

GE Source World Guide (2004). GE Source World Guide website. Bahrain Demographics. Retrieve July 14, 2004 from: http://www.gesource.ac.uk/worldguide/html/821_people.html

Hauben, M. (2002). History of ARPENET: The “open” history of the ARPANET/ Internet. Retrieved November 19, 2003, from: http://www.dei.isep.ipp.pt/docs/arpa.html 
Haugland, S., and Wright, J. (1997). Young Children and Technology: A world of discovery. Boston, MA.: Allyn and Bacon.

Hall, B., and Snider, A. (2000). Glossary: The Hottest Buzz Word in the Industry. Learning, 44(4), $85-104$.

Hannafin, R., and Savenye, S. (1993). Technology in the Classroom: The teachers' new role and resistance to it. Educational Technology, 33(6), 26 - 31.

Hara, N., and Kling, R. (2000). Students' Distress with a Web-based Distance Education Course: An ethnographic study of participants' experiences. Information, Communication and Society 3(4), $557-579$.

Hartly, J., and Robertson, D. ( 2001). e-learning in Schools. Times Educational Supplement, 12(5), $16-20$.

Jamlan, M. (2002). Distance Learning Between Current Practice and Future Perspectives. Journal of Educational and Psychological Sciences, 3(1), 138 - 162.

Kleiman, G. (2000). Myths and Realities About technology in K-12 Schools. LNT Perspectives. The Online Journal of the Leadership and the New Technologies Community. Retrieved April 25, 2004 from: http://www.edc.org/LNT/NewsIssue14/feature1.htm

Kook, J. (1997). Computers and Communication Networks in Educational Settings in the Twenty First Century: Preparation for Educator's New Roles. Educational Technology, 37(2), 56 -60 .

Laurillard, D. (2002). Rethinking Elementary Teaching. London: Routledge.

Magnusson, M., and Svensson, L. (2000). Technology and Pedagogy in e-Learning: A case study of attitudes among teachers. Proceedings of the First International Conference on Knowledge Management. 1 - 14.

Mason, M. (2001). Globalising Education: Trend and Applications. London: Routledge.

McKenzie, J. (1998). The Information Literate School Community. From Now On. The Educational Technology Journal, 8(1), 22 - 27.

Minton, M. (2000). Is Your Organization Ready for e-learning? Communication Project Magazine, 15(3), 1 - 8.

Nitko, A. J. (1996). Educational Assessment of Students. Second Edition. Mahwah, NJ.: Merrill, an Imprint of Prentice Hall.

O’Donnell, J. (1991). Teacher Perception of Their e-learning Needs to Integrate e-learning into Classroom Instruction. Unpublished doctoral dissertation, University of Southern California at Los Angeles.

Salmon, G. (2000). e-Moderating the Key to Teaching and Learning Online. London: Clays Ltd. 
Schofield, J. (1997). Internet, Classroom Cultures and Changes. Cambridge, MA.: Cambridge University.

Spender, D. (2001). e-Learning: are Universities Prepared? In Online Learning in a Borderless Market. Conference proceedings at a conference held at Griffiths University Gold Coast Campus (p. 59-63). Canberra: Department of Education, Training and Youth Affairs.

Teather, D. (2000). How to Learn the Hardware Way. The Guardian, 23(3), 77 - 79

Urdan, T., and Weggen, C. (2000). Corporate e-learning Exploring. A New Frontier. Computer News, 53(11), 35 - 36.

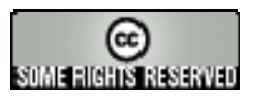

